\title{
An Investigation on TiNi Intermetallic Produced by Electric Current Activated Sintering
}

\author{
N. ERGIN AND O. OZDEMIR* \\ Technology Faculty, Department of Metallurgy and Materials Engineering, Sakarya University \\ Esentepe Campus, 54187 Sakarya, Turkey
}

\begin{abstract}
In this study, TiNi intermetallic compounds were produced by electric current activated sintering in open air under an uniaxial pressure of $200 \mathrm{MPa}$ at a maximum of $1200 \mathrm{~A}$ for 10 min using Ni powder (99.8\% purity, 4-7 $\mu \mathrm{m}$ ), Ti powder (99.5\% purity, less than $44 \mu \mathrm{m}$ ). The elemental powders were mixed in the stoichiometric ratio corresponding to the TiNi intermetallic at molar proportion of 1:1. Scanning electron microscopy and X-ray diffraction analysis were used to characterize produced samples. X-ray diffraction studies revealed that the dominant phases are $\mathrm{TiNi}, \mathrm{NiTi}_{2}, \mathrm{Ni}_{3} \mathrm{Ti}, \mathrm{TiO}$, and $\mathrm{Ni}_{2} \mathrm{Ti}_{3}$. Scanning electron microscopy examinations showed a dense microstructure with very low amount of porosity. The relative density of test materials measured according to Archimedes' principle was $96.8 \%$, and the microhardness of materials was about $773.6 \pm 123 \mathrm{HV}_{0.05}$.
\end{abstract}

DOI: 10.12693/APhysPolA.123.248

PACS: 81.20.Ev, 81.40.Pq

\section{Introduction}

Intermetallic compounds are promising materials for high temperature applications as structural or non-structural materials (heat resistance, corrosion resistance, electronic devices, magnets, superconductors). Among the intermetallics, titanium-nickel (TiNi) alloys are extensively applied in mechanical, electric, microelectromechanic, chemical, aerospace, and medical industries due to their excellent shape memory effect, high erosion resistance, high damping capacity, toughness, ductility and biocompatibility [1-5].

Intermetallic compounds are prepared by a variety of methods including classic melting and casting, roll compaction, practiced by conventional metallurgy, via powder consolidation by powder metallurgy methods, combustion synthesis with thermo-mechanical treatment and mechanical alloying, etc. Among these, electric current activated/assisted sintering (ECAS) technique, loose powders or a cold formed compact to be consolidated are inserted into a container which is heated to and then held at the desired temperature, while pressure is applied and maintained for a given period of time. Heat is provided by passing an electric current through the powders and/or their container, thus exploiting the consequent Joule effect. On the contrary, in conventional high pressure (HP) techniques, the powder container is typically heated by radiation from the enclosing furnace through external heating elements and convection of inert gases if applicable. Therefore, the sample is heated as a consequence of the heat transfer occurring by conduction from the external surface of the container to the powders. The resulting heating rate is then typically slow and the process can last hours. In addition, a lot of heat is wasted

*corresponding author; e-mail: oozdemir@sakarya.edu.tr as the whole volume of space is heated and the compact indirectly receives heat from the hot environment. On the other hand, ECAS processes are characterized by the efficient use of the heat input, particularly when electrically insulating container is used and the electric current is applied for extremely short duration (down to few hundreds of microseconds) $[6,7]$.

In the present study, TiNi intermetallic compound was produced by ECAS method and the properties were also investigated using various techniques including scanning electron microscopy (SEM) and X-ray diffraction (XRD). In order to determine hardness and density of the test materials, a Vickers indenter and Archimedes' technique were utilized.

\section{Experimental details}

In order to manufacture TiNi intemetallic compound as starting materials titanium powder (99.5\% purity, $45 \mu \mathrm{m})$, nickel powder (99.8\% purity, $4-7 \mu \mathrm{m})$ were used. $\mathrm{Ti}$ and $\mathrm{Ni}$ powders were mixed in stoichiometric ratio corresponding to the TiNi intermetallic phase, in a molar proportion of $1: 1$. Prior to sintering, the mixture was cold pressed into a cylindrical compact in a metal die under a uniaxial pressure of $200 \mathrm{MPa}$. The diameter and height of the compact samples were $15 \mathrm{~mm}$ and $5 \mathrm{~mm}$, respectively. The production of TiNi intermetallic compound was performed by electric current activated sintering at a maximum of $1200 \mathrm{~A}$ for $10 \mathrm{~min}$. The relative density and porosity of the synthesized sample were measured using Archimedes' method. The test materials were polished and etched using a solution of $\mathrm{CH}_{3} \mathrm{COOH}$ $(50 \mathrm{vol} . \%)+\mathrm{HNO}_{3}(30 \mathrm{vol} . \%)+\mathrm{HCI}$ (20 vol.\%). The microstructures and phase constitutions were characterized by SEM-energy dispersive spectroscopy (SEM-EDS) XRD. Microhardness of sintered test materials was determined by using micro-hardness tester with a load of 50 for $15 \mathrm{~s}$ on polished cross-sectional area of test materials. 


\section{Results and discussion}

The microstructures of TiNi intermetallic compound is shown in Fig. 1. As it can be seen in Fig. 1, the TiNi intermetallic revealed a dense microstructure with very low amount of porosity. The process is combined effects of both the electric current and pressure. The electric current has been used for the ignition of the mixture of powders. In general, the compact can be heated by both Joule heat and the heat of exothermic reaction during the reaction period. Once the chemical reaction ignited, the temperature rapidly rises after reaction, heat is supplied only by the resistance heating, and the temperature increase is slower than that during reaction [8]. Moreover, the electric current was also used for supplying the energy needed to complete the reaction and to generate the TiNi in situ. In the present study, in order to decrease the amount of porosity and obtain a dense structure a pressure is directly applied on the powders placed in the mould. The electrical current was passed through the compact to complete the reaction for $10 \mathrm{~min}$.

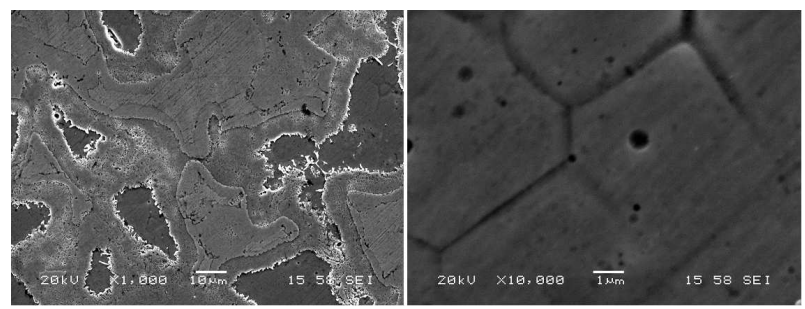

Fig. 1. SEM images of TiNi samples.

The phases formed in the TiNi compounds include TiNi as a major phase, along with $\mathrm{NiTi}_{2}, \mathrm{Ni}_{3} \mathrm{Ti}, \mathrm{TiO}$, and $\mathrm{Ni}_{2} \mathrm{Ti}_{3}$ phases. These phases were confirmed by XRD analysis (Fig. 2). It was observed that open atmosphere can result in formation of oxides.

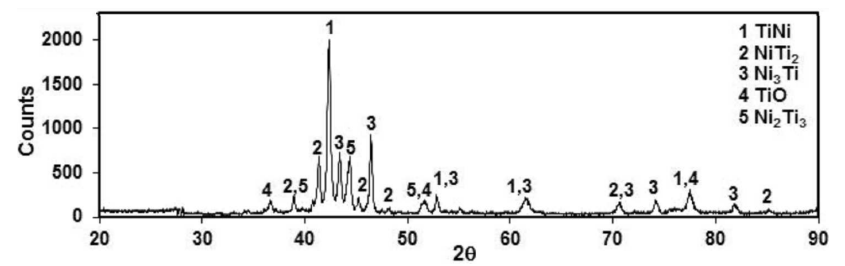

Fig. 2. X-ray diffraction patterns of TiNi samples.

As it can be seen in Fig. 2, the reaction was not completed in the TiNi compound synthesis. It is possible to say that the holding time or applied current is insufficient for the formation of TiNi phases in the sintering, completely. The distribution of alloying elements in the samples was determined by EDS analysis (Fig. 3).

The hardness of TiNi samples measured using the Vickers indentation technique with a load of $0.5 \mathrm{~N}$ were approximately $773.6 \pm 123 \mathrm{HV}_{0.05}$. The hardness result of present study is in good agreement with open literature values especially for $\mathrm{Ti}_{2} \mathrm{Ni}$ compound [2]. The relative densities of the samples calculated according to Archimedes' principle was approximately $96.8 \%$.

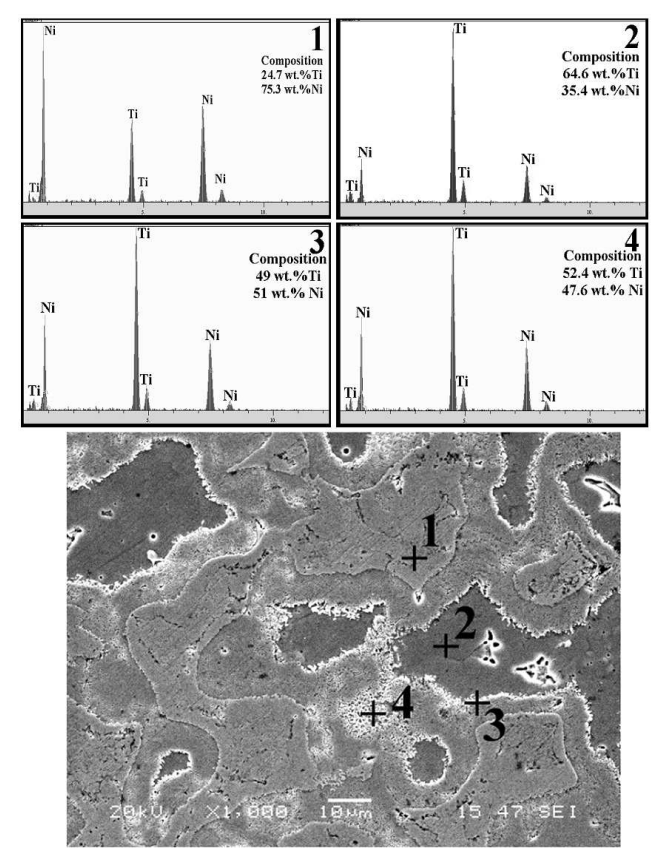

Fig. 3. EDS analysis of TiNi.

\section{Conclusions}

TiNi intermetallic compounds produced by electric current activated sintering has low porosity. The presence of TiNi as a major phase, along with $\mathrm{NiTi}_{2}, \mathrm{Ni}_{3} \mathrm{Ti}$, $\mathrm{TiO}$ and $\mathrm{Ni}_{2} \mathrm{Ti}_{3}$ phases was confirmed by XRD analysis. The relative density is $96.8 \%$ for TiNi intermetallics compound. The microhardness of materials measured by the Vickers indenter was about $773.6 \pm 123 \mathrm{HV}_{0.05}$.

\section{References}

[1] C. Sierra, A.J. Vazquez, Intermetallics 14, 848 (2006).

[2] G. Fei, W. Hua-Ming, Trans. Nonferrous Met. SOCC 17, 1358 (2007).

[3] X.M. Qui, M.G. Li, D.Q. Sun, W.H. Lui, J. Mater. Proc. Technol. 176, 8 (2006)

[4] S. Mridha, H.S. Ong, L.S. Poh, P. Cheang, J. Mater. Proc. Technol. 113, 516 (2001)

[5] C. Zhang, Z.N. Farhat, Wear 267, 394 (2009).

[6] J. Rodriguez, S.O. Moussa, J. Wall, K. Morsi, Scr. Mater. 48, 707 (2003)

[7] R. Orru, R. Licheri, A.M. Locci, A.G. Cincotti, Mater. Sci. Eng. R 63, 127 (2009)

[8] J. Liu, Y. Yang, K. Feng, D. Lu, J. Alloys Comp. 476, 207 (2009) 